\title{
ФОРМИРОВАНИЕ ЧУВСТВА СОЦИАЛЬНОГО ОДИНОЧЕСТВА (ФИЛОСОФСКИЙ АНАЛИЗ)
}

\begin{abstract}
А.В. Миронов
Анализ феномена социального одиночества, переживаемого индивидом, предполагает выявление составляющих положений, реконструкцию механизма воздействия различных общественных компонентов на массовое и индивидуальное сознание, определение условий деструкции взаимоотношений гражданина и среды его публичного предъявления. Масштабность задачи требует ввода категорий, содержащих функциональное многообразие социальной жизни. Схематичность позволяет очертить объем задействованного общественного пространства, в котором индивид пытается установить контакты с общностью, к которой он принадлежит по праву деятельности, происхождения, социального позиционирования. Современная социология, как западная, так и отечественная, проявляя интерес к массовому поведению, утрачивает интерес к индивиду как носителю духовности. В обобщающих подходах представлены, прежде всего, толпа, аудитория, электорат, профессиональная группа. Личностные ощущения, метаморфозы нравственного, эстетического, ценностного характера остаются, как правило, вне рассмотрения. Человеческое «я», включенное в динамику общественных связей, болезненно реагирует на ложь, лицемерие несправедливость, равнодушие, имущественное неравенство, обман и другие негативные проявления системы социального устройства. Комплекс требований, предъявляемых гражданину государством, общественной системой, сталкивается с его собственными взглядами, представлениями, убеждениями, сформировавшимися в результате негативного опыта соприкосновения с социальностью, и перестает восприниматься как значимая компонента жизни. Сегменты различных форм
\end{abstract}

Актуальні проблеми духовності:

зб. наук. праць / Ред.: Я.В. Шрамко

Вип. 15. - Кривий Ріг, 2014, 103-114 
воздействия на гражданина складываются в устойчивое чувство неприятия общества.

Основополагающим понятием в рассмотрении данного вопроса можно назвать «социальный организм» - структуру, включающую отношения между индивидом и социальным миром. Она проецирует их исходя из задач выживания, стабильности, осуществления функций связи и контактов, возможностей позитивного сотрудничества, то есть максимальной пользы для всех членов, включенных в сферу его влияния. Человеку предоставляются условия реализовать свои интересы материальные и духовные - посредством действий, апробированных общественной средой. М. Вебер выделяет в качестве критерия «социально ориентированные» поступки, то есть поведение, имеющее целью установление контакта с другими. Включенность в общественную группу обусловливает специфику действий, определяет направленность к традиционно принятому, ожидаемому, одобряемому. Столкновение с установками, возникающими без участия индивида, вынужденно трансформирует его сознание, побуждая осмыслить мотивы собственных действий.

Социальное действие, подобно любому другому поведению, может быть: 1) целенаправленным, если в основе его лежит ожидание определенного поведения предметов внешнего мира и других людей и использование этого ожидания в качестве «условий» или «средств» для достижения своей, рационально поставленной и продуманной цели; 2) ценностно-рациональным, основанным на вере в безусловную эстетическую, религиозную или любую другую-самодовлеющую ценность определенного поведения как такового, независимо от того, к чему оно приведет; 3) аффективным, прежде всего, эмоциональным, то есть обусловленным аффектами или эмоциональным состоянием индивида; 4) традиционным, то есть основанным на длительной привычке [1, с. 628$]$.

Использование данных модусов поведения соотносится с ситуациями, в которые попадает человек в социальном поле. Степень его амбиций, подготовленности, культурных и образовательных навыков выражают личностные претензии на закрепление в обществе. Мотивация может быть различной: (1) личные интересы (благополучие, комфорт, удовлетворение повышенных потребностей); (2) общественные (всеобщее благо, совершенствование общезначимых положений, процветающее государство, народное счастье); (3) личные особенности (тщеславие, честолюбивые планы, признание, слава, поклонение); (4) зависимость от комплекса мотивов. Таким образом, выстраивается вектор действий, обращенный к отдельным лицам, группам или всему обще- 
ству в целом. Исходя из уверенности в равноправии, социальной справедливости, свободе выбора, зафиксированных в законах, индивид реализует свое право человека и гражданина на участие в социальном процессе.

Взаимодействие с общественной структурой развивается в двух вариантах: сотрудничество и соперничество. Предложение знаний, силы, энергии, контроля можно сравнить с услугами, в добровольном порядке предоставляемыми сообществу. Востребованность их может служить знаком одобрения и принятия индивида с равными правами в участники общественного процесса. Отторжение - нежелание допустить в круг действующих лиц. Следует сделать акцент на параллельности мнений: последовательность выстраивается предлагаемыми обстоятельствами, новациями, динамикой, открытостью или закрытостью общества, политической ситуацией и т. д. Актуализация контактов варьируется, усложняя осознание своей роли и мотивов действий. Сотрудничество символизирует обоюдную заинтересованность в совместных целях, подкрепляя таковые поддержкой, одобрением, наградой. Стороны выступают в качестве социальных партнеров с общими правилами игры, нормами, взаимными договоренностями. Эмоциональный посыл сбалансирован признанием конструктивных намерений. Содействие решению актуальных задач возвышает личность в собственных глазах, придает осмысленность существованию. Другой вид социального взаимодействия - конкуренция и соперничество. Индивид попадает в ситуацию недоброжелательства, зависти, неприязни. Стороны не имеют общей цели и, как следствие, преследуют различные интересы, при этом для участников диалога формально они могут быть выражены в общих понятиях. Важным моментом является личная позиция.

\footnotetext{
Личная привязанность порождает парадокс преданности: личность утверждает свою независимость, повинуясь велениям своей совести, то есть обязательствам, возлагаемым личностью самой на себя. М. Лютер выразил эту ситуацию своим заявлением: «На том стою и не могу иначе» [3, с. 313].
}

Самоотдача добровольна и благородна, но ей приходится сталкиваться с бюрократическим официозом, некомпетентностью, равнодушием, чванством, где основной мотив деятельности - сохранение служебного положения, соответствие требованиям власти, корысть и безответственность. Несовместимость позиций моделирует конфликт, перерастающий в нарушение социальных связей, он же генерирует ощущение социальной жертвы. 
Интеракционизм индивида и общества включает адаптацию в систему через социальные стереотипы, т. е. схематизированные образцы поведения, содержание которых наполняется государством, социальными институтами, церковными организациями. Идеи, внедряемые в контекст данных представлений, имеют существенное значение для поддержания стабильности, порядка, жизненной ориентации граждан. Важной характеристикой является масштаб распространения и признания. Чем большее количество граждан разделяет эти представления, тем большая вероятность для них оформиться в устойчивые традиции. Половые, национальные, религиозные, профессиональные признаки связывают воедино и облегчают поиск границы между «своим» и «чужим». Группа, выделившаяся по определенному критерию, стремится защитить свои ценности, утвердить свой статус, добиться признания в качестве значимой социальной единицы. Общественное мнение регулирует поведение индивида, его проявления, чувства, демонстрируемые окружающим. Оно вправе принять, отвергнуть, осудить, одобрить, тем самым, возвести барьеры на пути в группу или дать разрешение на вступление в нее. Человек в процессе социальной деятельности, воспитания, наставлений приобретает знания о сложном комплексе неписанных правил и вынужден выбирать, соотнося свои планы, мечты, желания, потребности с тем образом, который он должен принять в надежде на их осуществление. Т. Парсонс вводит понятие «актер», идентичное по сущности социальной роли.

1. Социальная система должна располагать достаточным количеством составляющих ее «актеров», адекватно побуждаемых действовать в соответствии с требованиями ее системы ролей. 2. Социальная система не должна придерживаться таких образцов культуры, которые либо не могут дать определение хотя бы минимального порядка, либо предъявляют людям совершенно невыполнимые требования и, тем самым, порождают отклонения и конфликты $[4$, с. 66$]$.

Общество и государство создают данные стереотипы, адаптируя к своим задачам. Совершается акт манипуляции общественным сознанием, т. е. расширенное вовлечение гражданина в политическую и социальную деятельность. Долженствование, присущее стереотипу, снимает и личную ответственность за его осуществление. Стандарт освящен социальным признанием, большинством, поддерживающим его. Навязываются примитивные аксиомы: «только так и никак иначе», «быть таким, как все» и т. п.

Внутренняя природа человека может не соответствовать социальному стереотипу. Чем больше вопросов к социальной системе, тем 
меньше доверия к предлагаемым стандартам. Расхождение «я» и официально одобренных представлений объясняется набором личностных принципов и качеств. Человек не удовлетворен отводимой ему ролью, его духовное развитие вышло за пределы принятого на себя статуса с четко выраженной направленностью (член корпорации, партии, религиозной общины, общественного объединения). Ощущение многообразия бытия мотивирует пересмотреть нормы поведения, в противном случае, стереотипы становятся сдерживающим началом, не позволяют расширять контакты, иметь собственное мнение и озвучивать его, допускать действия, противоречащие установкам группы, вступать в конфликт с теми институтами власти, которые позиционируются как социальные союзники. Интерес к собственной жизни инициирует новые формы атрибуции, адекватные измененному сознанию. Социальная общность воспринимает такую ситуацию как протестную, она несет угрозу не только стабильности, но и самому существованию группы. Ю. Хабермас отмечает, что человек не может «совершить побег в анонимность третьего лица, и поскорее должен потребовать признания в качестве индивидуализированного существа» [5, с. 205]. Инаковость воспринимается на обыденном уровне проявлением удивления, подозрительностью, непониманием. Прежняя социальная роль не выполнима, так как нарушается принятая прежде логика «игры», обнажается искусственность предписаний, их надуманность, а в некоторых случаях антигуманность. Индивид терзается потерей друзей, прежних единомышленников, средой коммуникации. Его переживания усиливаются враждебностью, бойкотом со стороны группы. Разорванность сознания можно охарактеризовать утратой привычного. Отказ от стереотипов - обдуманный акт несогласия, разъединения, в результате которого меняется направление жизни, вместе с ним и все духовные составляющие.

Свобода раскрепощает, лишает заданности и вместе с этим уходит привлекательность стереотипа. Эксперименты, которые может позволить себе человек, наталкивают на качественно новые поведенческие формы, соответствующие новому набору ценностей. С утратой стереотипов, прежнего образа жизни индивид оказывается в ситуации социального одиночества, т. к. утрачен допуск к системе, открывающей возможности общения, действий, совместных мероприятий. Вариативность изолированности прямо пропорциональна нежеланию пользоваться стереотипами: от внутригрупповых до общепринятых. Следовательно, чувство одиночества в обществе меняется по мере нигилистических настроений. Подчеркнутое отрицание касается не только фор- 
мализированной стороны тех или иных действий, через него посылается знак о неприятии конкретных сфер (формы правления, нарушении законов, отношения к гражданам, коррупции, экономической модели) или всего социального организма (по определению, он не может быть другим - более честным, гуманным, справедливым, нравственным). Личность использует этот ход, заявляя о прекращении прежних отношений с социумом. Можно сделать вывод, что использование или неиспользование стереотипов нельзя рассматривать исключительно в прагматическом понимании. Употребление их служит признанием социальной реальности и подчинению ее требованиям, т. е. демонстрацией себя в статусе законопослушного гражданина. Пренебрежение ими - сознательный шаг к конфронтации, обострению отношений. Обособленность от социальной системы позволяет сконцентрироваться на себе, подбирать адекватные конструкции поведения в соответствии с мировоззренческими установками.

Одним из приоритетов социального взаимодействия выступает достижение социального согласия между индивидом и обществом. В нем раскрывается общность интересов, идеалов, целей, объединяющих человеческое сообщество в целостный организм. Совпадение точек зрения служит показателем осознания совместных проблем, вопросов, ситуаций, волнующих обе стороны и нашедших совпадающие подходы к их разрешению, приемлемые для участников диалога. Достигнутая конвенция и ее соблюдение позволяет выстраивать соразмерный ответ обществу, основанный на уверенности в соблюдении базовых принципов, прописанных в законах и существующих в виде моральных предписаний. В согласии проявляется одобряемость конкретных действий, акций, мероприятий, содержание которых ведет к общему благу, включая интересы одного, отдельно взятого человека, делающего вывод и оценивающего их с позиции социального индивида. Совпадение взглядов может служить стимулом участия в предлагаемых общественных проектах. В качестве примера можно привести формирование общенациональной идеи, защиту коренных интересов, обсуждение жизненно важных решений, сотрудничество с гражданскими институтами. В зависимости от достигнутого согласия относительно фундаментальных моментов существования наступает фаза единомыслия, наиболее плодотворный период в государственной истории. Социальный организм должен объяснить, оправдать, подтвердить правильность положений, которые становятся частью общественного сознания. «Я», выражая одобрение, принимает на себя ряд обязательств (самоотдача, энтузиазм, жертвенность), в том числе и негативного порядка (понижение 
материального уровня, отказ от удовольствий и т. д.). Будущее должно компенсировать переживаемые трудности. Примирение с действительностью расширяет личностный диапазон поступков, способствует открытости, новаторству, адаптивности, т. е. мир становится своим, в нем возможно проявление себя как личностного начала. Согласие видоизменяет картину окружающего, человек стремится найти аргументы оправдания негативного или вовсе их не заметить.

Установка на положительное восприятие событий общественной жизни особенно проявляется в оценке социальных отношений. Обоснование несовершенства социальных контактов в таких случаях подразумевает чуждое влияние, корыстные интересы отдельных лиц, личную амбициозность. Эти положения становятся частью конвенции. Сообразно ей, принимая главное, индивид соглашается и с его атрибутикой. Общество убеждает в неразрывности части и целого, опираясь на поддержку государства, заинтересованного в социальном мире. Его ресурсы (контролируемая система образования, средства массовой информации, социальная реклама и др.) служат созданию образа гармонии между гражданами.

В социальном согласии имеют место два специфических аспекта, требующие отдельного рассмотрения. Индивид выбирает то, что подкреплено силой, законом, поддержкой, влиянием. Он не задается вопросами о том, что представляет собой диктующее начало, какими средствами оно добилось успеха, какое право распоряжаться чужой жизнью, взглядами, духовными принципами. Перманентное согласие придает комфорт и благополучие жизненным ощущениям. Между прежней точкой зрения и новыми убеждениями не возникает противоречия, смена происходит безболезненно, так как мировоззрение не превратилось в личностно значимое, не проникло в сущность человека, а выступало в виде необходимой формы существования в социальном мире. Подобный пример изобразил итальянский писатель А. Моравиа в романе «Конформист»: согласие превращается в соглашательство. Единственным ориентиром становится желание угодить власти, конкретным людям, избранному кругу. Поведенческий модус уподобляется приоритетному в обществе, позволяя скрыться за безличностью, отказаться от индивидуальности. Беспринципность, моральная аморфность, лицемерие ведут к утрате личности, создавая отрицательный фон общественной жизни. Столкновение с подобной социальной непривлекательностью отторгает от социальной системы, ассоциируя с ней насилие над свободой человека.

Стагнационное согласие- одобрение стабильности в ущерб пози- 
тивным изменениям. Застойные явления мотивированы страхом потерять имеющееся. Инициатива, динамика, трансформация несут с собой опасность рисков для государства и общества, которые стремятся сохранить, во что бы то ни стало, существующий порядок власти, экономики, социальных отношений. Страх изменений определяется отсутствием новых идей, угрозой потери личного влияния, идеологической заданностью. Осуществляется обмен между населением и властной структурой: удовлетворение базовых потребностей на согласие смириться с конкретной формой правления, определенным кругом лиц, политической партией, родственным кланом. От человека требуется покорность и действия в заданных границах. Его волеизъявление не играет роли, отношения с обществом парализованы, а личностный порыв грозит внести элемент анархии в устоявшуюся структуру, поэтому пресекается. Вынужденная формализация отношений осмысливается как бездушие, невнимание, цинизм. Гражданин отвечает подобным: закрепляя согласие в виде бессодержательного договора, в котором опущена личная парадигма. Индивид переносит жизненно важное в иные сферы, свободные от официального контроля.

Материальный интерес преподносится как основополагающий принцип в социальном согласии. Имущественное расслоение, обнищание, преступность - факторы, понижающие социальное согласие. На этой почве возникает конфликтность между различными группами населения и государством, устраняющимся от поддержки большинства. Но в не меньшей мере самочувствие человека в обществе определяется доверием, испытываемым к сообществу, выполняющим взятые на себя обязательства. Участник социального процесса должен обладать уверенностью, что общество по праву распоряжается социальным капиталом (налоги, средства коммуникации, история этноса, возможности правовых институтов, достижения предыдущих поколений и др.). Если власть социально ориентирована и прислушивается к ожиданиям сограждан, то в этом случае поддерживается баланс интересов, в противном - наступает фаза недоверия, определяющая нравственный климат в обществе. Ее можно уподобить «циничной враждебности»: стороны ожидают обмана, предательства, неравноценного обмена своими ресурсами. Личный опыт обобщает отрицательные последствия столкновения с социальной системой и формирует с прицелом на будущее негативную парадигму отношений. Неудовлетворенность действиями политических лидеров, чиновников, структурирующих социальное пространство, порождает раздражение, переходящее в протест. На этой основе происходит объединение по 
недоверию к власти, раскалывающее общество на правых и виноватых.

В патерналистских системах представлены два варианта, взаимовытекающие друг из друга: доверие к обществу сопряжено с недоверием к себе. На авторитетное начало возлагается решение всех фундаментальных вопросов, оно должно определять перспективу, отличать важное от второстепенного. Человек руководствуется предлагаемыми директивами, утрачивая способность к самостоятельному осмыслению социальных фактов, ожидая готовую схему, матрицу, включающую отношения, ценности, поведенческий стандарт. Чем выше доверие, тем безусловнее выполнение предписаний. Если система претерпела крах, собственноручно расписалась в несостоятельности, отказывается транслировать ожидаемые шаблоны, ее влияние признается завершенным и индивид вынужден обращаться к себе или искать иную модель с теми же функциями (партия, общественная организация, объединение по религиозным, национальным, профессиональным признакам). В периоды социальных трансформаций в патерналистском обществе можно наблюдать кризис отношений во всех сферах, но наиболее драматично переживается вакуум указаний, направлений. Предоставленный самому себе, индивид обращает агрессию к институтам, не оправдавшим доверие, вымещая на них глубокое разочарование в себе и собственной доверчивости. Единственный вариант в такой ситуации - «спасение поодиночке», замыкаясь на личное «я», воспитывая доверие только к самому себе. Поэтому синдром недоверия к обществу становится стимулом разобраться с собственным внутренним миром, обратиться к самопознанию или искать союз, опирающийся на солидарность отвергнутых. Социальное одиночество выступает результатом разобщенности между двумя центрами - индивидом и обществом. Деформация базовых понятий общественной жизни, каковым является социальное доверие, разрушает потребность участвовать в социально значимых действиях.

Поведение в обществе регулируется с помощью правил и убеждений, которые становятся основой взаимодействия между членами социума. Воля государства (нормы права) и общественное мнение (нормы морали) формируют институциональный образец, включающий социальные императивы. Как отмечает Э. Дюркгейм, сходные значения и сходные реакции позволяют добиться единства через общезначимое. Норма - критерий приемлемого и неприемлемого поведения, который служит для распознаваемости поступка и их оценки. В случае конфликта между индивидом и обществом вердикт выносится, исходя из содержания нормы. Группа, принимающая набор правил, пози- 
ционирует их как обязательства, а не соответствующее требованиям объявляется отклонением. Но важность выполнения их для участников может быть не однозначной.

Индивидуальные нормы, как и социальные, не ориентируются на результат, и источником их является стремление избежать чувства смятения и вины. В то же время они не зависят от одобрения или неодобрения других людей, поскольку совсем не обязательно разделяются ими $[2$, с. 20$]$.

В случае представления нормы, наполненной аморальным содержанием (на территории постсоветского пространства на бытовом уровне и коррупция считается приемлемым вариантом поведения, так как произошел перекос стандартов, с признанием положений, принятых в криминальных группах, в общественной повседневности), индивид ее игнорирует, сообразовываясь с личными нравственными принципами. Тем не менее, такое развитие событий может быть воспринято как девиантное. Индивидуальный анализ предлагаемого акцентируется на противоречиях между коллективными представлениями и личной позицией. Трудность толкования понятия «отклоняющееся» связано с прессингом социального окружения, унификацией человека. Неучастие индивида в том, что у него вызывает сомнение и, как следствие, устранение из коммуникации, воспринимается как изъян, ущерб, наносимый самому себе, и вызывает непонимание и недоброжелательность.

Рассмотрение социальных категорий, определяющих контуры взаимодействия индивида и общества, позволяет сделать вывод о комплексности социального влияния на модусы поведения. По мере усложнения структуры общества человек сталкивается с ситуациями, требующими личного выбора. Фатальная разобщенность, ставшая обыденным явлением, генерирует проблемы связанные не только с экономическими показателями, но, прежде всего, изменением нравственной единицы измерения социума. Она тиражирует чувства, эмоции, рациональные конструкции, мешающие осуществить полноценный контакт со средой общественного обитания. Недоверие, несогласие, неприятие стереотипов, отказ от устоявшихся норм инициируют социальную пассивность, переходящую в апатию. Человек сталкивается с мнимостями, а не подлинными социальными фактами единства и сплоченности. Капитал общества девальвируется, граждане не желают терпеть официальную ложь, неоправданную пропаганду, коррупцию, манипулирование сознанием. Экономический детерминизм частично объясняет барьеры, возникающие в социальном пространстве: разрыв между богатыми и бедными, отсутствие 
гарантий, предоставляемых государством, падение жизненного уровня и т. д. Но без общего нравственного фундамента индивид и общество начинают выступать как две автономные системы, а если утрачены точки соприкосновения, невозможно достичь консенсуса сторон.

Поскольку мы сливаемся с группой и живем ее жизнью, мы не можем избежать ее влияния, но, с другой стороны, поскольку мы обладаем индивидуальностью, отличающей нас от нее, мы оказываем ей сопротивление и стремимся уклониться от ее влияния. [...] Нас увлекает социальное чувство, но, вместе с тем, мы отдаемся настроению, отвечающему нашей личной природе [6, с. 310].

Вытеснение человека из процесса участия происходит двумя путями: (1) создание «охранительных барьеров», наделенных властными полномочиями, то есть подкрепленных правовой составляющей (их цель - удержать интересы тех, кто желает сохранить баланс в отношениях с гражданами, не переделывая конструкцию социального организма, оставить возможности использовать свое положение в целях личного обогащения. Соответственно, происходит лоббирование определенных проектов через законодательные органы) и (2) недопущение граждан к реальному механизму принятия решений (опасность ротации, концентрация власти в конкретных руках и нежелание делить ее с кем-либо, страх общественного контроля и т. д.). Наталкиваясь на формализацию, обман, равнодушие, откровенную алчность индивид отступает от своих прежних намерений совершенствовать социальное пространство и занимает пассивную позицию в отношении общественной системы. Его не устраивает статус «одобряющего», он отказывается от косвенного подкупа, посулов, социальных «подачек», а социальные институты не проявляют стремления к поиску единства, довольствуясь теми ресурсами (административным, управленческим и др.), которыми располагают. Потребность в диалоге угасает, и человек переносит желание обрести единство, проявить свои способности, направленные на благо всех, в иную область или «консервирует» их на будущее. Эмоциональное и рациональное сопротивление месту и роли, отведенным человеку в обществе, трансформируется в устойчивое моральное чувство неприятия системы социальных связей, обоснованное недоверием, несогласием, отрицанием определенных норм и стереотипов, выражающих порядок включения в коммуникацию на уровне группы и всего сообщества. Многообразие составляющих уплотняется до тотального неодобрения и оформляется в позицию социального одиночества, то есть сознательного обособления от существующих форм социальной организации. 


\section{Литература}

[1] Вебер М. Избранные произведения. - М. : Прогресс, 1990.

[2] Дюркгейм Э. Самоубийство. Социологический этюд. - М. : Мысль, 1994.

[3] Полани М. Личностное знание. - М. : Прогресс, 1985.

[4] Тернер Дюс. Структура социологической теории. - М. : Прогресс, 1985.

[5] Хабермас Ю. Понятие индивидуальности // Хабермас Ю. О человеческом в человеке. - М. : Политиздат, 1991. - С. 195-206.

[6] Elster J. Social norms and economic theory // The Journal of Economic Perspectives. - 1989. - V.3, No 4. - C. 89-117.

Надійшла до редакиї 16 січня 2014 р. 